\title{
Reproduction and Its Discontents in Mexico. Childbirth and Contraception from 1750 to 1905. Por Nora E. Jaffary. Chapel Hill: University of North Carolina Press, 2016, $302 \mathrm{pp}$.
}

\author{
Ricardo A. Fagoaga Hernández \\ Historiador

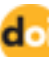 \\ DOI: I0.2490I/rehs.v40i159.633
}

\section{(c) ) EY-NO}

Reproduction and Its Discontents in Mexico. Childbirth and Contraception from 1750 to 1905. Por Nora E. Jaffary. Chapel Hill: University of North Carolina Press, 2016, 302 pp. por Ricardo A. Fagoaga Hernández se distribuye bajo una Licencia Creative Commons Atribución-NoComercial 4.o Internacional.

La historia de la medicina, la demografía histórica y la historia del derecho han estudiado diferentes aspectos de la reproducción femenina de los diferentes grupos socioeconómicos que componían a la población urbana y rural del periodo colonial y nacional de México. Nora E. Jaffary ha realizado una investigación que analiza a profundidad aspectos de la sexualidad femenina, el embarazo y el parto, entretejiendo diferentes aspectos demográficos, legales y científicos que abarcan más de 150 años de historia mexicana. El análisis de Jaffary se centra en dos argumentos principales. El primero, la construcción de diferentes discursos de la virtud femenina y la sexualidad, matizados por las características de la estructura social y los cambios que se dieron en la transición de colonia a nación en México. El segundo, el análisis de diversas interconexiones de diferentes elementos (sociales, judiciales, científicos) a lo largo de un siglo y medio que sirvieron para forjar la idea de nación a través de la capacidad de las mujeres de dar a luz a los futuros ciudadanos mexicanos.

El honor y la virtud femenina, a lo largo de los seis capítulos que componen el libro, sirven como detonadores para abrir la discusión de cómo la virginidad, el embarazo, la anticoncepción y el aborto, el infanticidio, los nacimientos de infantes con deformaciones, el alumbramiento, la ginecología y la obstetricia fueron sujetos de la legislación, construidos por el discurso científico de Occidente en constante fricción con las prácticas "tradicionales" de matronas y parteras, y que se transformaron de ser elementos del ámbito privado para convertirse en debates públicos. Para conjugar cada una de las partes de la reproducción femenina, Jaffary revisó vastas colecciones archivísticas en España, Ciudad de México y Oaxaca, para concentrar la información judicial de más de 150 años que le permitió reunir un corpus de casos relacionados con la reproducción femenina y que son la riqueza de cada uno de los capítulos. 
El capítulo uno, dedicado a la virginidad, deja en claro que en el periodo prehispánico no era relevante para los grupos mesoamericanos la virginidad y a partir de la inculcación de la religión católica se convirtió en un "fetiche" que sirvió para construir la reputación pública de las mujeres, y que les otorgó un "valor social" en la sociedad colonial hasta que se consolidó como una idea de virtud femenina en el siglo XIX. Por lo anterior, Jaffary centra su atención en la virginidad y las consecuencias del desfloramiento, por promesas de matrimonio que no se cumplieron o por violación. La violencia hacia las mujeres, en especial, a las solteras, era considerada atroz por las consecuencias sociales de la pérdida de la virginidad y por el crimen en sí mismo. Es en este capítulo en que la autora introduce la importancia de parteras y matronas, como expertas en reconocer los genitales femeninos, para ayudar en los juicios criminales. En la época colonial, los magistrados preferían que las mujeres que asistían a las parturientas peritaran en los casos de violación y así ayudar a dictar sentencia. Con la profesionalización de la medicina y su interés en la sexualidad femenina, las parteras y matronas fueron desplazadas hasta que se consolidó la ginecología a finales del siglo XIX.

La importancia de las parteras también es central en el capítulo dos, donde Jaffary estudia la concepción y el embarazo. La incertidumbre de las mujeres en saber si estaban embarazadas estaba íntimamente ligada a ese grupo de mujeres con conocimientos relacionados al embarazo, que tenían conocimiento de plantas y hierbas que ayudaban a regular la menstruación (incluso provocarla) y que conocían bien las manifestaciones y cambios en el cuerpo de las mujeres durante el embarazo, y podían manejar diferentes situaciones durante el alumbramiento. En este capítulo es donde la autora expone con mayor fuerza su argumento de que las parteras mantuvieron su estatus profesional frente a los médicos hasta principio del siglo XX, a pesar de que el gremio científico (compuesto de varones) intentaba minimizar y prohibir las prácticas de las mujeres relacionadas con la sexualidad de las mujeres.

Los siguientes dos capítulos, tres y cuatro, están íntimamente ligados a las parteras y sus conocimientos. La legislación indiana y las leyes nacionales de México prohibían el aborto y castigaban el infanticidio. Los juicios que recoge Jaffary, que abarcan diferentes lugares y periodos históricos, le ayudan a problematizar la evolución de la criminalización del aborto, especialmente, el infanticidio. Para los magistrados era extremadamente difícil juzgar y dictar sentencia a las mujeres que alumbraban en ámbitos privados, con apenas la presencia de una partera. Aunque matronas y parteras podían asegurar que los infantes nacieron vivos, las probabilidades de una muerte prematura ayudaban a cerrar los juicios sin dictar una sentencia clara. Por supuesto, estos juicios eran de mujeres del pueblo y que no pertenecían a la elite. También, las parteras y matronas podían ser acusadas de causar abortos, no sólo por sus conocimientos en hierbas y plantas, sino por el manejo y acomodo de los infantes en el útero de la madre antes de nacer.

Es necesario señalar que Jaffary desarrolla el argumento de que la criminalización del aborto y el infanticidio, más bien los juicios, incrementaron en los registros judiciales cuando la práctica médica se profesionalizó a lo largo del siglo XIX. Al mismo tiempo, se transformaron los espacios privados en donde se llevaba a cabo el alumbramiento y se cambiaron por espacios púbicos, donde la intervención de médicos y la necesidad del registro de infantes de parte del 
Estado (registro civil) eran instrumentos para medir el crecimiento de población y fue preámbulo del surgimiento del nacionalismo obstétrico que está bien documentado en los siguientes dos capítulos.

Los nacimientos de infantes con deformaciones, monstruosidades, le sirven a Jaffary en el capítulo cinco para explicar cómo estos nacimientos sirvieron como instrumento discursivo para fortalecer el patriotismo criollo del siglo XVIII que buscaba erradicar la idea de inferioridad de América en el discurso científico europeo. En el siglo XIX, estos casos sirvieron para fomentar la idea de fertilidad y, al mismo tiempo, para construir un discurso científico alrededor del cuerpo de la mujer mexicana.

El capítulo seis, dedicado a la ginecología, la obstetricia y el alumbramiento, reafirma la importancia de las parteras al momento del alumbramiento y en la importancia de la cesárea como un procedimiento que sólo se podía llevar a cabo para salvar la vida del recién nacido y lograr bautizarlo. Con la profesionalización de la práctica médica en el siglo XIX, la obstetricia y el uso de instrumental durante el alumbramiento ganaron fuerza en la práctica, reforzándose en los estudios publicados que debatían las virtudes de nuevos descubrimientos. Para que la ciencia tuviera un campo fértil, y pudiera responder a las constantes comparaciones que se hacían con los descubrimientos europeos, fue necesario que los médicos crearan un discurso alrededor del cuerpo de la mujer mexicana y, en especial, de su capacidad de reproducirse biológicamente.

En Reproduction and Its Discontents in Mexico, Nora E. Jaffary logra conjugar las prácticas e ideas médicas, jurídicas y religiosas alrededor de la reproducción de las mujeres. En el centro de su análisis, las parteras, mujeres con conocimiento y prácticas "tradicionales", se explica cómo gracias a sus conocimientos participaron como expertas en el ámbito judicial, además de ayudar en incontables embarazos y partos. Como señala la autora desde el inicio de su libro, su análisis bien sirve para repensar el aborto, la reproducción y la construcción del cuerpo de las mujeres en el siglo XXI. 